\title{
Current and Future Status of Laparoscopy in Gynecologic Oncology
}

\author{
Derzeitiger und zukünftiger Stellenwert der Laparoskopie \\ in der gynäkologischen Onkologie
}

Authors

Affiliations
S. Rimbach ${ }^{1}$, K. Neis ${ }^{2}$, E. Solomayer ${ }^{3}$, U. Ulrich ${ }^{4}$, D. Wallwiener ${ }^{5}$

1 Gynäkologie und Geburtshilfe, Landeskrankenhaus Feldkirch, Feldkirch, Austria

2 Praxis Frauenärzte am Staden, Saarbrücken

${ }^{3}$ Gynäkologie und Geburtshilfe, Univ.-klinik des Saarlandes, Homburg/Saar

${ }^{4}$ Gynäkologie und Geburtshilfe, Martin-Luther-Krankenhaus, Berlin

${ }^{5}$ Universitätsfrauenklinik Tübingen, Tübingen

\section{Key words \\ - laparoscopy \\ - gynecologic oncology \\ - ovarian malignancy \\ - endometrial cancer \\ - cervical cancer \\ Schlüsselwörter \\ - Laparoskopie \\ - gynäkologische Onkologie \\ - Ovarmalignom \\ - Endometriumkarzinom \\ - Zervixkarzinom}

Deutschsprachige Zusatzinformationen online abrufbar unter: www.thieme-connect.de/ ejournals/toc/gebfra

\section{received $\quad 12.8 .2014$ \\ revised 22.8.2014 \\ accepted 22.8.2014}

\section{Bibliography}

Dol http://dx.doi.org/

10.1055/s-0034-1383075

Geburtsh Frauenheilk 2014; 74 : 852-859 @ Georg Thieme Verlag KG Stuttgart · New York . ISSN 0016-5751

\section{Correspondence}

\section{PD Dr. Stefan Rimbach}

Landeskrankenhaus Feldkirch

Gynäkologie und Geburtshilfe

Carinagasse 47

6800 Feldkirch

Austria

stefan.rimbach@vlkh.net

\section{Abstract \\ $\nabla$}

Laparoscopy is playing an increasingly important role in gynecologic oncology. The benefits of minimally invasive surgery for oncology patients and the quality of this treatment are well documented. Outcomes and quality of minimally invasive surgical procedures to treat cervical cancer were evaluated based on retrospective and casecontrol studies; outcomes and quality after minimally invasive treatment für early-stage low-risk endometrial cancer were also assessed in prospective randomized studies. If indicated, laparoscopic lymphadenectomy is both technically feasible and oncologically safe. Adipose patients in particular benefit from minimally invasive procedures, where feasible. The potential role of laparoscopy in neoadjuvant therapy for ovarian cancer and in surgery for early-stage ovarian carcinoma is still controversially discussed and is currently being assessed in further studies. Using a minimally invasive approach in gynecologic oncology procedures demands strict adherence to oncological principles and requires considerable surgical skill.

\section{Zusammenfassung \\ $\nabla$}

Der Laparoskopie kommt in der gynäkologischen Onkochirurgie eine zunehmend wichtige Rolle zu. Die allgemeinen Vorteile minimalinvasiver Operationstechniken sind auch für onkologische Patientinnen mittlerweile gut belegt bei gleichzeitiger Wahrung der onkologischen Behandlungsqualität. Dies wurde für die operative Therapie des Zervixkarzinoms anhand retrospektiver und Fallkontrollstudien, für das frühe Low-Risk-Endometriumkarzinom auch prospektiv-randomisiert erfolgreich gezeigt. Eine indizierte Lymphonodektomie lässt sich sowohl technisch als auch onkologisch sicher per Laparoskopie durchführen und gerade adipöse Risikopatientinnen profitieren, wenn durchführbar, vom minimalinvasiven Vorgehen. Beim Ovarialkarzinom wird eine mögliche Rolle des laparoskopischen Zugangs im Rahmen neoadjuvanter Therapiekonzepte und zur operativen Therapie in Frühstadien kontrovers diskutiert und erfolgt daher derzeit unter Studienbedingungen. Die Durchführung gynäkoonkologischer Eingriffe mit minimalinvasivem Zugang setzt nicht nur die Einhaltung onkologischer Prinzipien, sondern auch erhebliches operationstechnisches Know-how voraus.

on laparoscopic radical hysterectomy to treat cervical carcinoma. Since then, numerous laparoscopic gynecologic oncology procedures have been carried out, and a number of studies have assessed the outcomes after minimally invasive surgical procedures.

In the German Society for Gynecology and Obstetrics (Deutsche Gesellschaft für Gynäkologie und Geburtshilfe [DGGG]), the Study Group for Gynecologic Endoscopy (Arbeitsgemeinschaft Gynäkologische Endoskopie [AGE]) promotes advanced training and scientific debate on the use of endoscopic surgery for all indications in surgical gynecology. 


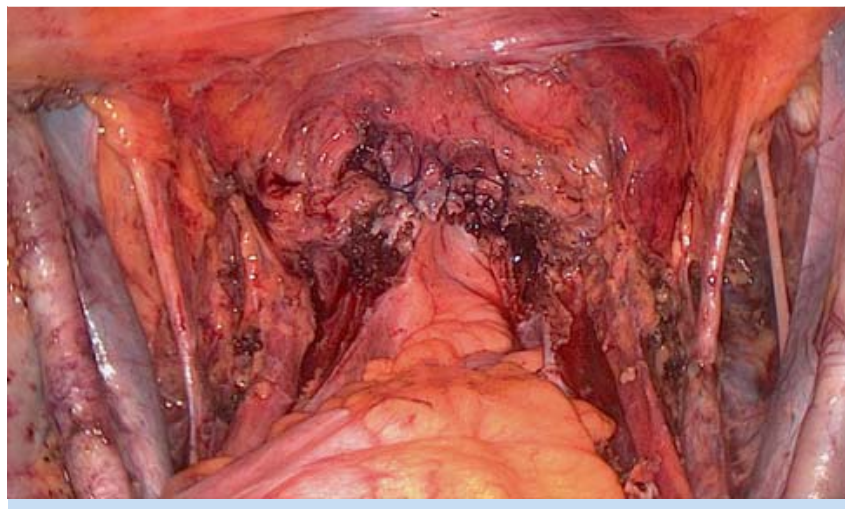

Fig. 1 Operation site after laparoscopic pelvic lymphadenectomy and radical hysterectomy for cervical cancer stage pT1b1.

From this vantage point, we present an overview of the current status and possible future developments in laparoscopy in gynecologic oncology. This examination will focus on the most common current applications of laparoscopy in the treatment of uterine carcinoma and on the debate on potential applications to treat early-stage ovarian cancer.

\section{Cervical Cancer}

\section{$\nabla$}

\section{Laparoscopic procedures: different approaches}

With the exception of mesometrial resection [6], the reported methods for radical hysterectomy are based on the Wertheim [7] and the Schauta [8] procedures developed over 100 years ago. Laparoscopic radical hysterectomy represents, first and foremost, a variation in the method of approach, but otherwise it largely adheres to the principles and operative techniques of open surgery ( $\bullet$ Fig. 1).

While there does not appear to be a "best" method for radical hysterectomy [9], the choice for or against a specific operative procedure (or radiotherapy) requires surgeons to take account of the tumor stage, oncologic risk factors (histology), lymph node involvement, menopausal status, the patient's wish to have children, therapy-specific short and long-term effects, anesthesiological and clinical problems (operability), and the general condition and personal circumstances of the affected patient. This assessment also includes examining the potential benefits offered by a minimally invasive approach. At the end of the 19th and beginning of the 20th century, mortality after radical hysterectomy surgery was high. Some reports describe a mortality of $30 \%$ after abdominal and $12 \%$ after vaginal surgery. In the $1950 \mathrm{~s}$, these figures were still between 2 and 15\% for Wertheim procedures and between 1 and $6 \%$ for Schauta procedures [10]. Now the figure is less than $1 \%$ and, in addition to improving oncological outcomes, the focus has shifted to minimizing postoperative morbidity.

\section{Current status of studies: laparoscopic vs. open surgery} In accordance with general findings comparing open and laparoscopic surgery, studies on the use of laparoscopy in cervical cancer also unanimously state that while laparoscopic and laparoscopically assisted procedures often require longer operation times, they result in a lower loss of blood, require fewer transfusions and are associated with shorter hospitalization times [1118].
To assess oncologic effectiveness, numerous studies have evaluated the number of resected lymph nodes and parametrial and vaginal resection margins in laparoscopic procedures compared to open surgery. The majority of these studies are retrospective analyses and their findings suggest that outcomes, as measured by these parameters, are equivalent [16-19].

An HTA report published in 2010 [20] and a systematic review published in 2012, which included data on 1339 laparoscopically operated patients from 21 studies [21], came to the same conclusion.

Two prospective randomized studies differed from each other with regard to surgical technique and results. The study by Naik et al. [22] involved small stage IB tumors with 15 patients randomized to undergo laparoscopically-assisted radical vaginal hysterectomy (LARVH) or radical abdominal hysterectomy (RAH). The clinical short-term benefit of laparoscopically assisted procedures was confirmed, but laparoscopically assisted procedures were also found to be less radical, as the mean resected vaginal cuff ( 1.26 vs. $2.16 \mathrm{~cm}$ ) and mean resected cardinal ligament (1.3 vs. $2.79 \mathrm{~cm}$ ) lengths were shorter. Simsek et al. [23] carried out a prospective randomized evaluation of 88 patients, 35 of whom underwent laparoscopic total radical hysterectomy. Based on the parameters "number of resected lymph nodes" and "histologically verified, tumor-free vaginal and parametrial resection margins" in patients with parametrial involvement (11.4\% of laparoscopic procedures and $16.9 \%$ of open surgical procedures), they found no difference in radicality compared to open surgery.

The most important parameters from an oncologic standpoint are rate of recurrence and survival probability, and data on these parameters are plentiful, although all of the data come exclusively from retrospective and paired-cohort or case-control studies [24-29]. However, there are no significant differences between the findings in these studies and outcomes after open surgery ( Table 1).

Prospective randomized survival data are not available in the literature making it impossible to do a Cochrane analysis offering definitive recommendations [30].

\section{Recommendations and guidelines}

The available data have found their way into national und international guidelines. The Scottish Intercollegiate Guidelines Network already stated in 2008 that laparoscopic vaginal radical hysterectomy was a safe and effective alternative to conventional abdominal radical hysterectomy to treat FIGO stage IB1 cervical cancer [31].

In its 2010 guideline, the National Institute for Health and Clinical Excellence in the UK presented sufficient evidence on the effectiveness and safety of laparoscopic radical hysterectomy to treat early-stage cervical cancer to support the use of this procedure [32].

The new German S3-Guideline on the Treatment of Cervical Cancer is, as yet, only available in its consultation-stage version; it states with a recommendation grade of 0 and a level of evidence of 2++ that laparoscopic radical hysterectomy can be an alternative procedure to abdominal open radical hysterectomy [33]. 
Table 1 Retrospective and case-control studies comparing laparoscopic and laparoscopically assisted procedures with open radical hysterectomy.

\begin{tabular}{|c|c|c|c|c|c|}
\hline Authors & Stage & Follow-up & \multicolumn{2}{|c|}{ Survival/Recurrence } & \multirow[t]{2}{*}{ Significance } \\
\hline Toptas et al. 2014 & $|A 2-| B 1$ & mean: 43 months & 3-year PFS & 3-year OS & \\
\hline - $\mathrm{TLRH} n=22$ & & & 86 & 100 & n.s. \\
\hline ORHn=46 & & & 91 & 95 & n.s. \\
\hline Kong et al. 2014 & $\mathrm{IB}-\mathrm{II} \mathrm{A}>3 \mathrm{~cm}$ & up to 4 years & DFS, \% & & \\
\hline - $\mathrm{LRH} n=40$ & & & 97.9 & & n.s. \\
\hline ORH $\mathrm{O}=48$ & & & 97.5 & & n.s. \\
\hline Park et al. 2013 & IB2-IIA2 & 5 years & DFS, \% & & \\
\hline L $\mathrm{LRH} n=115$ & & & 83 & & n.s. \\
\hline ORH $n=188$ & & & 83 & & \\
\hline Taylor et al. 2012 & $\mid \mathrm{A} 2-\mathrm{IB} 1$ & up to 8 years & DFS, \% & & \\
\hline D $\mathrm{LRHn}=6$ & & & 100 & & n.s. \\
\hline $\mathrm{ORH} n=12$ & & & 100 & & \\
\hline Nam et al. 2012 & $\mid A 2-\| A$ & paired cohort study & recurrence-fre & & \\
\hline - $\mathrm{LRH} n=263$ & & & 92 & & n.s. \\
\hline - $\mathrm{ORH} n=263$ & & & 94 & & \\
\hline Pahisa et al. 2010 & $\begin{array}{l}\text { case-control } \\
\text { up to } 11 \text { year }\end{array}$ & istorical control group, & recurrence, \% & OS $\%$ & \\
\hline - LAVRH $n=67$ & & & 5.9 & 97 & n.s. \\
\hline - $\mathrm{ORH} n=23$ & & & 13 & 91,3 & n.s. \\
\hline
\end{tabular}

Abbreviations: TLRH: total laparoscopic radical hysterectomy; LRH: laparoscopic radical hysterectomy; ORH: open radical hysterectomy; LAVRH: laparoscopically-assisted vaginal radical hysterectomy; OS: overall survival; DSF: disease-free survival; PFS: progression-free survival

\section{Endometrial Cancer \\ $\nabla$}

Current status of studies: laparoscopic vs. open surgery Many articles have reported on the benefits of laparoscopic procedures rather than open surgery to treat early-stage endometrial cancer. Similar to cervical cancer, reported benefits generally include fewer perioperative complications, less loss of blood, fewer transfusions and shorter hospital times as well as a higher quality of life after laparoscopic hysterectomy compared to open abdominal hysterectomy; these findings were recently confirmed in a meta-analysis of 4 randomized controlled studies [34] and a Cochrane analysis of 8 prospective randomized studies with 3644 patients ( Table 2) [35]. No statistically significant differences were found with regard to perioperative morbidity (RR: 0.76; 95\% CI: 0.32-1.79), blood transfusion rates (RR: 0.55; 95\% CI: 0.21-1.49), bladder lesions (RR: 0.49; 95\% CI: $0.13-$ 1.86), intestinal injuries (RR: 1.49; 95\% CI: 0.39-5.72) and vascular injuries (RR: 0.43; 95\% CI: 0.08-2.32). Blood loss was lower (RR: -106.82 ; 95\% CI: -141.59 to -72.06 ) and there were fewer serious postoperative complications (RR: 0.58 ; $95 \% \mathrm{CI}$ : $0.37-$ 0.91 ) in the laparoscopy group. From an oncologic standpoint, there were no differences between laparoscopic and open surgery with respect to disease-free interval $(\mathrm{HR}=1.13 ; 95 \% \mathrm{CI}$ : $0.90-1.42$ ) and overall survival ( $\mathrm{HR}=1.14 ; 95 \% \mathrm{CI}$ : 0.62-2.10). In the largest prospective randomized study carried out to date, the Gynecologic Oncology Group (GOG) LAP2 study [36,37], 2616 patients were randomly allocated to receive either laparoscopy or laparotomy treatment. The 5-year survival rate was almost identical in both groups at $89.9 \%$.

The use of laparoscopy and laparotomy to treat high-risk endometrial cancer are compared in a retrospective multicenter study [38] and a prospective randomized study in the above-mentioned GOG LAP2 study. The study by Fader et al. also included patients with grade G3 tumors. Two thirds of patients were operated on using robotic minimally invasive surgery and one third underwent laparoscopic surgery. There were no differences with regard to age, comorbidities, BMI, previous abdominal opera- tions, tumor stage, adjuvant therapy and histology. A comparison of the different operative techniques found no difference in disease-free interval and overall survival. A subgroup analysis done in the GOG LAP2 study also found no significant differences with regard to recurrence-free survival, even in the high-risk cohort (unfavorable tumor stage, myometrial infiltration of $50 \%$ and more, lymphangitic carcinomatosa, unfavorable histology). However, it should be noted that this subgroup analysis of high-risk cancers had not been defined in advance as one of the study endpoints and consequently lacks sufficient statistical power.

\section{Recommendations and guidelines}

The AGO recommendations $[39,40]$ include two statements on the use of laparoscopy to treat endometrial cancer:

- "Examination of short-term postoperative morbidity shows that laparoscopy is superior to open surgery. The long-term morbidity is the same." And

- "For low-risk cases the oncologic results for laparoscopic and open surgery are comparable. The data on high-risk cases is still insufficient".

International guidelines, e.g. from the UK and France, also support the use of laparoscopy to treat endometrial cancer [41,42], but they emphasize the importance of special training and the fact that surgeons must have advanced laparoscopic skills.

\section{Risk factor obesity}

Endometrioid endometrial carcinoma is strongly associated with obesity and diabetes mellitus. This represents a risk factor for perioperative complications, resulting in longer operation times, higher blood loss and higher transfusion rates. Laparoscopy is more difficult in obese patients. Access to the peritoneal space, establishment of pneumoperitoneum, and access to pelvic organs and structures and the paraaortic region can be more difficult, and anesthesiologic complications can be an impediment to lymphadenectomy and even hysterectomy procedures. Neverthless, despite these difficulties, the success rate for laparoscopy procedures performed in obese patients with early-stage endometrial 


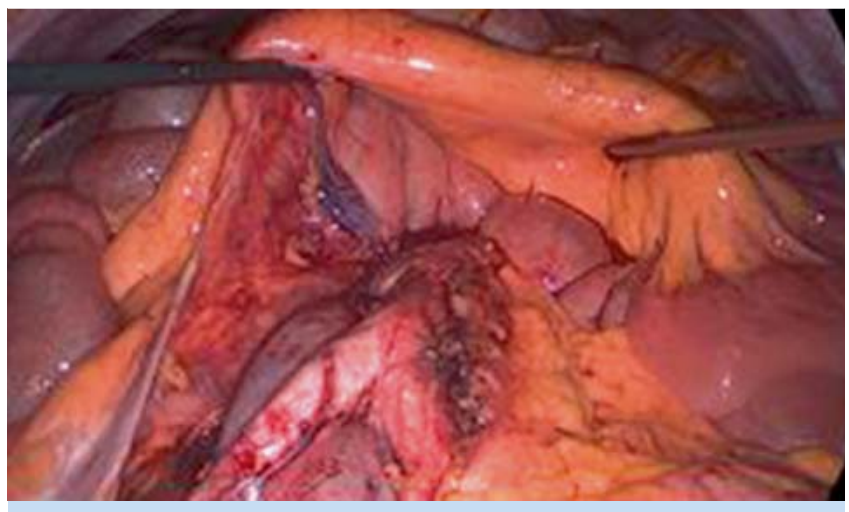

Fig. 2 Laparoscopic paraaortic lymphadenectomy.

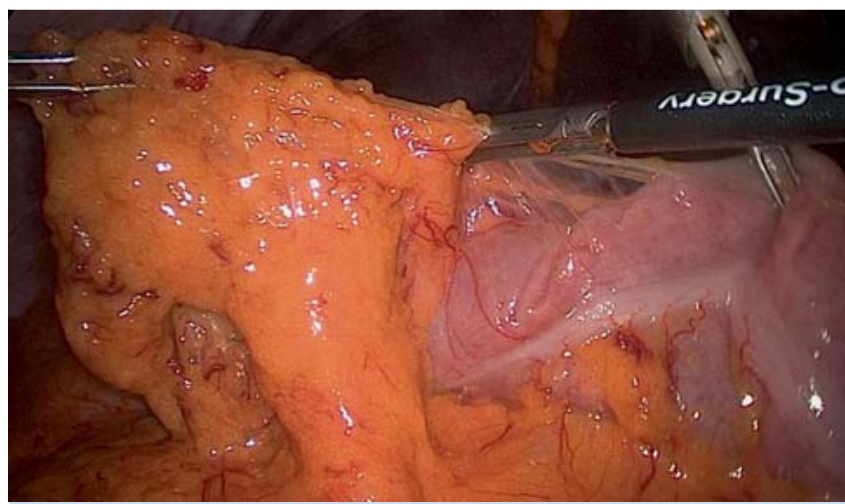

Fig. 3 Laparoscopic omentectomy. cancer was $89 \%$. Although the operation times were longer, there were significantly fewer postoperative complications compared to open procedures, and the subsequent quality-of-life score was higher [43-46]. It would therefore appear that laparoscopy is particularly suitable to treat obese patients. This is an important consideration as obesity represents a significant risk factor for postoperative complications in patients with early-stage endometrial cancer but does not appear to constitute an oncologic prognostic factor [46].

\section{Lymphadenectomy in Uterine Cancer}

Laparoscopic lymphadenectomy is as safe as open laparotomy to treat lymphadenectomy $[19,43,44]$. Most studies found no significant difference in the number of lymph nodes resected by laparoscopy or laparotomy. Oncologically acceptable pelvic and paraaortic lymphadenctomy can also be carried out using a laparoscopic approach ( $\bullet$ Fig. 2). Although laparoscopic conversion rates of up to $5 \%$ have been reported in the literature (and up to $12 \%$ of cases in obese patients), these laparoscopic conversions were rarely precipitated by the lymphadenectomy.

The morbidity associated with lymphadenectomy can be reduced with the use of the sentinel lymph node concept. Robust data on the use of this concept in patients with cervical cancer has shown that the sentinel lymph node technique is reliable in patients with tumors measuring less than $2 \mathrm{~cm}$ and that the technique can be carried out laparoscopically with satisfactory results [12, 47]. A sensitivity of $93.5 \%$ and a negative predictive value of 99.1\% have been reported using technetium and blue-dye labeling, meaning that the technique can be used in clinical practice. Optimal bilateral sentinel lymph node detection combined with ultrastaging using histological sections and immunohistochemistry can additionally reduce the false-negative rate [48].

Use of sentinel lymphadenectomy in endometrial cancer is also being trialed. However, the studies published to date investigated different areas of application (cervix, subendometrial, intramural) and used different agents (technetium, blue dye or both). In a recent meta-analysis (2071 patients, 35 studies with information on false-negative rates, 51 studies with information on detection rates), the pooled detection rate was $77.8 \%$ (95\% CI: 73.5-81.5\%) and the pooled sensitivity was $89 \%$ (95\% CI: $83-$ $93 \%$ ) [49]. Studies again confirmed the benefits of pathologic ultrastaging [50]. The current debate focuses less on the question of which operative approach to use (laparoscopy or open surgery); rather, controversy centers on the oncologic validity of the sentinel lymph node concept in endometrial cancer, and the method is not currently considered as established [49,51-54]. Thus, in cases where histology or staging has indicated a need for lymphadenectomy, complete pelvic and paraaortic lymphadenectomy is still considered indispensable, even if sentinel lymph node biopsy has been performed and the findings are negative.

Table 2 Cochrane analysis for endometrial cancer (Galaal et al. 2012).

\begin{tabular}{|c|c|c|c|c|}
\hline Outcome or subgroup title & No. of studies & No. of participants & Statistical method & Effect size \\
\hline \multicolumn{5}{|l|}{ Comparison 1. Primary outcomes } \\
\hline 1 Overall survival & 3 & 359 & Hazard Ratio (random, 95\% CI) & $1.14(0.62 ; 2.10)$ \\
\hline 2 Recurrence-free survival & 4 & 2975 & Hazard Ratio (random, 95\% Cl) & $1.13(0.90 ; 1.42)$ \\
\hline \multicolumn{5}{|l|}{ Comparison 2. Secondary outcomes } \\
\hline 1 Perioperative death & 5 & 3233 & Risk Ratio (IV, random, 95\% CI) & $0.76(0.32 ; 1.79)$ \\
\hline 1.1 Within 30 days & 4 & 2950 & Risk Ratio (IV, random, 95\% CI) & $0.68(0.27 ; 1.71)$ \\
\hline 1.2 Within 6 weeks & 1 & 283 & Risk Ratio (IV, random, $95 \%$ CI) & $1.54(0.16 ; 14.61)$ \\
\hline 2 Estimated blood loss (ml) & 3 & 313 & Mean Difference (IV, random, 95\% CI) & $-106.82(-141.59 ;-72.06)$ \\
\hline 3 Blood transfusion required & 7 & 3572 & Risk Ratio (IV, random, 95\% CI) & $0.55(0.21 ; 1.49)$ \\
\hline 4 Bladder injury & 5 & 709 & Risk Ratio (IV, random, 95\% CI) & $0.49(0.13 ; 1.86)$ \\
\hline 5 Urethral injury & 2 & & Risk Ratio (IV, random, 95\% CI) & Subtotals only \\
\hline 6 Bowel injury & 3 & 489 & Risk Ratio (IV, random, 95\% CI) & $1.49(0.39 ; 5.72)$ \\
\hline 7 Vascular injury & 3 & 538 & Risk Ratio (IV, random, 95\% CI) & $0.43(0.08 ; 2.32)$ \\
\hline 8 Severe postoperative adverse events & 2 & 2923 & Risk Ratio (IV, random, 95\% CI) & $0.58(0.37 ; 0.91)$ \\
\hline
\end{tabular}


Results of a survey on the use of laparoscopy

to treat uterine cancer in Germany

AGE and AGO carried out a joint survey in 2012 to determine the prevalence of endoscopy to treat uterine cancer in Germany. As expected, endoscopy is much more common in procedures to treat endometrial cancer (around $80 \%$ of cases) compared to cervical carcinoma where endoscopy is only used in around $50 \%$ of procedures. The survey found that $58 \%$ of patients with endometrial cancer underwent total laparoscopic hysterectomy with adnexectomy and $32 \%$ had laparoscopically assisted vaginal hysterectomy with bilateral adnexectomy. Hospitals were asked about the numbers of patients operated on in their clinic using endoscopy and many hospitals stated that the majority of procedures ( $>75 \%$ ) for endometrial cancer were done laparoscopically (46 hospitals, corresponding to $36 \%$ of participating hospitals). However, only 14 hospitals $(11 \%)$ reported that procedures for cervical cancer were done laparoscopically. Given the greater technical skills required for this operation compared to procedures for endometrial cancer, this result does not come as a surprise [55].

\section{Ovarian Cancer}

The issue of using laparoscopic surgery to treat (presumed benign!) ovarian tumors was already discussed controversially in the 1990s and finally led to the guideline "Laparoscopic Surgery of Ovarian Tumors" jointly supported by the AGE and AGO. This guideline was first published in 1998 and has since been revised twice, the last time in 2008. It was the first guideline ever issued by the German Society for Gynecology and Obstetrics (DGGG). The latest version of this guideline [56] includes the statement: "patients with the incidental finding of ovarian cancer should not undergo further laparoscopic procedures (except to confirm the diagnosis); the definitive operation should be immediately or subsequently by laparotomy". The S3-Guideline on Diagnostics, Therapy and Follow-up of Malignant Ovarian Tumors published in 2013 [57] states that laparoscopic staging must not be done except as part of a study, due to the lack of controlled randomized data comparing laparoscopic and open procedures.

The literature on the use of laparoscopy to treat early-stage ovarian cancer goes back to case reports published in the early 1990s. Harry Reich was the first person to report a total laparoscopic hysterectomy procedure, describing the case of a patient who had refused open surgery and underwent laparoscopically assisted surgery instead [58]. Only a few years later, the introduction of laparoscopic lymphadenectomy with paraaortic lymph node resection allowed the technique to be evaluated as a tool for the staging of ovarian and Fallopian tube cancer [59], although the initial goal of these studies was simply to demonstrate the technical feasibility of the procedure. Right from the start, there were oncologic concerns about the laparoscopic means of access, particularly with regard to the emergence of port-site metastases in the region of the trocar puncture site, the risk of higher rates of intraoperative tumor findings, the validity of endoscopic staging and the oncologic outcome. Even in 2013, a Cochrane analysis came to the conclusion that the existing evidence is insufficient for a scientific evaluation of the benefits and risks of laparoscopy compared to laparotomy to treat early-stage (FIGO stage I) ovarian cancer [60]. However, this statement is based on a lack of randomized controlled studies.

The data on clinical feasibility is currently only available from non-randomized studies. The literature ranges from reports on laparoscopic procedures of early-stage ovarian cancer to studies on debulking procedures and the use of laparoscopy to treat recurrence [61]. In their search for an oncologically safe and technically feasible approach, a number of study groups appear to have changed their opinion in favor of a minimally invasive approach. Thus, in 1994, Canis et al. [62] were of the opinion that, because outcomes after using a laparoscopic approach to treat suspicious tumors were unclear, patients should undergo laparotomy. 10 years later [63] he and his colleagues held the opinion that restaging of early-stage ovarian cancer is a good indication for laparoscopy.

A recent publication from the United Kingdom described the biggest prospective single institution case series to date [64]. The study evaluated 35 patients with early-stage ovarian cancer operated on using a laparoscopic approach. The overall complication rate was $14 \%$ (5/35) and the conversion rate was $6 \%(2 / 35)$; overall survival was $100 \%$ and disease-free survival was $94 \%$ after a mean follow-up of 18 months (range 3-59). The authors concluded that laparoscopic staging was technically safe, oncologically acceptable and that the minimally invasive nature of the procedure meant that patients benefitted from a laparoscopic approch compared to laparotomy. An Italian study group arrived at similar results in a retrospective analyis of the data of 19 patients [65]. After a mean follow-up of 30 months (range 10-74), overall survival was $100 \%$ and disease-free survival was $84 \%$. The mean number of resected pelvic and paraaortic lymph nodes was 17 (range 7-27) and 14 (range 8-21), respectively.

A meta-analysis published in 2013 which looked at the data of 11 observational studies [66] reported a recurrence rate of $9.9 \%$ (95\% CI: 6.7-14.4\%) for a comparable mean follow-up time.

Currently laparoscopic procedures ( $\mathbf{O F i g} .3$ ) can still only be compared with outcomes after laparotomy on the basis of casecontrol studies.

Chi et al. [67] reported on 50 patients, 20 of whom were treated by laparoscopic surgery while 30 underwent open surgery. There were no significant differences with regard to the number of resected lymph nodes or omental specimen size. Operation times were longer with laparoscopy ( 321 vs. 276 minutes); blood loss and hospital times were lower after laparoscopy and there was no significant difference in the complication rates. The retrospective comparative study of Lee [68] comes to similar conclusions, noting that the complication rate after laparoscopic staging was significantly lower $(7.7 \%)$ than that of the laparotomy group (23.0\%). In another retrospective study, Koo et al. compared 24 patients treated laparoscopically with 53 patients who underwent open surgery. There were 2 recurrences in each group during the follow-up of 31 months, which corresponds to a recurrence rate of $8.3 \%$ in the laparoscopy group and $3.8 \%$ after laparotomy. The disease-free interval reported for the laparoscopy group (59 months) did not differ significantly from that of the laparotomy group at 66 months $(p=0.367)$ [69]. A recently published Italian case-control study [70] which evaluated 35 patients treated laparoscopically and 32 patients who underwent open surgery also looked at the issue of tumor cell spillage and subsequent upstaging. Spillage occurred in 6 cases in the laparoscopy group and in 4 patients in the open surgery group and did not differ statistically between groups ( $p=0.59$; OR: $0.7 ; 95 \%$ CI: $0.38-$ 1.27). Laparoscopy was associated with a significantly lower postoperative complication rate of $3 \%$ compared to $28 \%$ $(p=0.005)$. Five-year disease-free survival and overall survival rates were not affected by the surgical technique $(p=0.12$ and $p=0.26$, respectively; log-rank test). There were no differences 
in overall survival (OR: 0.5 ; $95 \% \mathrm{CI}$ : $0.21-1.21$ ). The authors concluded that laparoscopy was comparable to open surgery in terms of oncologic control but was associated with a lower perioperative morbidity.

The study of Fagotti published in 2013 [71] focused on a different aspect. In their study, laparoscopy was used to determine the feasibility of surgery in individual patients. No complications were reported after laparoscopy (exploratory staging laparoscopy). 148 of the 300 investigated patients were considered suitable for surgery and underwent laparotomy; R0 resection was achieved in $62.1 \%$ and reduction of the tumor to less than $1 \mathrm{~cm}$ in $22.5 \%$. A recent Cochrane analysis also evaluated the same issue and included a total of 7 studies in their analysis. Despite a number of caveats because of the limited numbers of patients and the different concepts used in the available studies, the authors concluded that laparoscopy was a promising approach [72].

\section{Conclusion}

\section{$\nabla$}

In summary, we can state that laparoscopy has an increasingly important role to play in gynecologic oncology surgery. The benefits of minimally invasive surgical procedures are also manifest for oncologic indications. Chief among these benefits is reduced postoperative short-term morbidity.

Laparoscopic radical hysterectomy is an established alternative to abdominal open radical hysterectomy for the surgical treatment of cervical cancer. Benefits of laparoscopy include less loss of blood, fewer transfusions and shorter hospital times. Operation times are usually longer. Oncologic radicality and recurrence and survival rates are comparable for both approaches; however, the relevant data is still predominantly based on retrospective studies.

Comprehensive prospective randomized studies attest to both the perioperative benefits and the oncologic equivalence of laparoscopy in low-risk endometrial cancer. Based on these data, the use of laparoscopic surgery is advocated in national and international recommendations and guidelines for the treatment of early-stage endometrial cancer.

If indicated, laparoscopic surgery is an oncologically safe and technically feasible procedure for systematic lymphadenectomy and sentinel lymph node biopsy. Obese patients in particular benefit from a minimally invasive approach. But problems with the technical viability of laparoscopy are higher in this patient population.

In contrast to uterine cancer, the question whether to use laparoscopy in ovarian cancer is still controversially discussed; the current recommendation is that laparoscopic surgery should only be used to treat ovarian cancer in clinical trials. Numerous reports in the literature from well-known oncologic centers point to the potential use of laparoscopy for staging, including neoadjuvant therapeutic approaches, and discuss the feasibility of using laparoscopy in the surgical treatment of early-stage cancers. However, experience is still limited, and meaningful prospective randomized studies which could provide reliable information on oncologic outcomes over and above the feasibility of the procedure are still lacking.

It remains to be seen to what extent robotic procedures, which were not the topic of the present overview, will transform the range of procedures used in gynecologic oncology surgery in future.
It must be emphasized how important it is that surgeons carrying out laparoscopic procedures have the necessary expert technical skills, training and experience, a point which all recommendations and guidelines are also agreed upon as the prerequisite for these procedures. If available, then endoscopic surgical procedures represent a successful way of offering the benefits of minimally invasive procedures to patients without having to make compromises in terms of oncologic safety.

\section{Conflict of Interest}

None.

\section{References}

1 Rosenoff SH, Young RC, Anderson $T$ et al. Peritoneoscopy: a valuable staging tool in ovarian carcinoma. Ann Intern Med 1975; 83: 37-41

2 Spinelli P, Luini A, Pizzetti P et al. Laparoscopy in staging and restaging of 95 patients with ovarian carcinoma. Tumori 1976; 62: 493-501

3 Querleu D, Leblanc E, Castelain B. [Pelvic lymphadenectomy under celioscopic guidance]. J Gynecol Obstet Biol Reprod (Paris) 1990; 19: 576578

4 Herd J, Fowler JM, Shenson D et al. Laparoscopic para-aortic lymph node sampling: development of a technique. Gynecol Oncol 1992; 44: 271276

5 Nezhat CR, Burrell MO, Nezhat FR et al. Laparoscopic radical hysterectomy with paraaortic and pelvic node dissection. Am J Obstet Gynecol 1992; 166: 864-865

6 Höckel M, Horn LC, Manthey $N$ et al. Resection of the embryologically defined uterovaginal (Müllerian) compartment and pelvic control in patients with cervical cancer: a prospective analysis. Lancet Oncol 2009; 10: 683-692

7 Wertheim E. Die erweiterte abdominale Operation bei Carcinoma colli uteri. Berlin: Urban \& Schwarzenberg; 1911

8 Schauta F. Die erweiterte vaginale Totalexstirpation des Uterus bei Kollumkarzinom. Wien, Leipzig: J. Safar; 1908

9 Ulrich U, Hrsg. Gynäkologische Onkologie. Ein Kompendium für die Klinik. Berlin, Boston: De Gruyter; 2013

10 Stoeckel W. Lehrbuch der Gynäkologie. Leipzig: S. Hirzel; 1955

11 Bogani G, Cromi A, Uccella S et al. Laparoscopic versus open abdominal management of cervical cancer: long-term results from a propensitymatched analysis. J Minim Invasive Gynecol 2014; DOI: 10.1016/j. jmig.2014.03.018

12 Díaz-Feijoo B, Gil-Moreno A, Pérez-Benavente MA et al. Sentinel lymph node identification and radical hysterectomy with lymphadenectomy in early stage cervical cancer: laparoscopy versus laparotomy. J Minim Invasive Gynecol 2008; 15: 531-537

13 Jackson KS, Das N, Naik R et al. Laparoscopically assisted radical vaginal hysterectomy vs. radical abdominal hysterectomy for cervical cancer: a match controlled study. Gynecol Oncol 2004; 95: 655-661

14 Malzoni M, Tinelli R, Cosentino F et al. Total laparoscopic radical hysterectomy versus abdominal radical hysterectomy with lymphadenectomy in patients with early cervical cancer: our experience. Ann Surg Oncol 2009; 16: 1316-1323

15 Zakashansky K, Chuang L, Gretz H et al. A case-controlled study of total laparoscopic radical hysterectomy with pelvic lymphadenectomy versus radical abdominal hysterectomy in a fellowship training program. Int J Gynecol Cancer 2007; 17: 1075-1082

16 Abu-Rustum NR, Gemignani ML, Moore K et al. Total laparoscopic radical hysterectomy with pelvic lymphadenectomy using the argon-beam coagulator: pilot data and comparison to laparotomy. Gynecol Oncol 2003; 91: 402-409

17 Frumovitz $M$, dos Reis R, Sun CC et al. Comparison of total laparoscopic and abdominal radical hysterectomy for patients with early-stage cervical cancer. Obstet Gynecol 2007; 110: 96-102

18 Wright JD, Herzog TJ, Neugut AI et al. Comparative effectiveness of minimally invasive and abdominal radical hysterectomy for cervical cancer. Gynecol Oncol 2012; 127: 11-17

19 van de Lande J. Open versus laparoscopic pelvic lymph node dissection in early stage cervical cancer: no difference in surgical or disease outcome. Int J Gynecol Cancer 2012; 22: 107-114 
20 Laparoscopic radical hysterectomy for early stage cervical cancer (structured abstract). Health Technology Assessment Database; 2010

21 Geetha P, Nair MK. Laparoscopic, robotic and open method of radical hysterectomy for cervical cancer: a systematic review. J Minim Access Surg 2012; 8: 67-73

22 Naik R, Jackson KS, Lopes A et al. Laparoscopic assisted radical vaginal hysterectomy versus radical abdominal hysterectomy-a randomised phase II trial: perioperative outcomes and surgicopathological measurements. Br J Obstet Gynaecol 2010; 117: 746-751

23 Simsek T, Ozekinci M, Saruhan Z et al. Laparoscopic surgery compared to traditional abdominal surgery in the management of early stage cervical cancer. Eur J Gynaecol Oncol 2012; 33: 395-398

24 Kong TW, Chang SJ, Lee J et al. Comparison of laparoscopic versus abdominal radical hysterectomy for FIGO stage IB and IIA cervical cancer with tumor diameter of $3 \mathrm{~cm}$ or greater. Int J Gynecol Cancer 2014; 24 : 280-288

25 Nam JH, Park JY, Kim DY et al. Laparoscopic versus open radical hysterectomy in early-stage cervical cancer: long-term survival outcomes in a matched cohort study. Ann Oncol 2012; 23: 903-911

26 Pahisa J, Martínez-Román S, Torné A et al. Comparative study of laparoscopically assisted radical vaginal hysterectomy and open WertheimMeigs in patients with early-stage cervical cancer: eleven years of experience. Int J Gynecol Cancer 2010; 20: 173-178

27 Park JY, Kim DY, Kim JH et al. Laparoscopic versus open radical hysterectomy in patients with stage IB2 and IIA2 cervical cancer. J Surg Oncol 2013; 108: 63-69

28 Taylor SE, McBee WC jr., Richard SD et al. Radical hysterectomy for early stage cervical cancer: laparoscopy versus laparotomy. JSLS 2011; 15: 213-217

29 Toptas T, Simsek T. Total laparoscopic versus open radical hysterectomy in stage IA2-IB1 cervical cancer: disease recurrence and survival comparison. J Laparoendosc Adv Surg Tech A 2014; 24: 373-378

30 Kucukmetin A, Biliatis I, Naik $R$ et al. Laparoscopically assisted radical vaginal hysterectomy versus radical abdominal hysterectomy for the treatment of early cervical cancer. Cochrane Database Syst Rev 2013; 10: CD006651

31 Scottish intercollegiate Guidelines Network. Management of cervical cancer. 2008; ISBN 9781905813247

32 Laparoscopic radical hysterectomy for early stage cervical cancer. 2010. Online: www.nice.org.uk./guidance/ipg338; last access: 16.09.2014

33 Leitlinienprogramm Onkologie (Deutsche Krebsgesellschaft, Deutsche Krebshilfe, AWMF). S3-Leitlinie Diagnostik, Therapie und Nachsorge der Patientin mit Zervixkarzinom, Langversion-Konsultationsfassung 0.1, 2014, AWMF-Registernummer: 032/033OL. Online: http://leitlinienprogramm-onkologie.de/Zervixkarzinom.75.0.html; last access: 16.09.2014

34 Zullo F, Falbo A, Palomba S. Safety of laparoscopy vs. laparotomy in the surgical staging of endometrial cancer: a systematic review and metaanalysis of randomized controlled trials. Am J Obstet Gynecol 2012; 207: 94-100

35 Galaal K, Bryant A, Fisher AD et al. Laparoscopy versus laparotomy for the management of early stage endometrial cancer. Cochrane Database Syst Rev 2012; 9: CD006655

36 Walker JL, Piedmonte MR, Spirtos NM et al. Laparoscopy compared with laparotomy for comprehensive surgical staging of uterine cancer: Gynecologic Oncology Group Study LAP2. J Clin Oncol 2009; 27: 5331-5336

37 Walker JL, Piedmonte MR, Spirtos NM et al. Recurrence and survival after random assignment to laparoscopy versus laparotomy for comprehensive surgical staging of uterine cancer: Gynecologic Oncology Group LAP2 Study. J Clin Oncol 2012; 30: 695-700

38 Fader AN, Seamon LG, Escobar PF et al. Minimally invasive surgery versus laparotomy in women with high grade endometrial cancer: a multi-site study performed at high volume cancer centers. Gynecol Oncol 2012; 126: 180-185

39 AGO; DKG; DGGG. Diagnostik und Therapie des Endometriumkarzinoms. Interdisziplinäre S2-Leitlinie, AWMF 032/034. Online: www. awmf.org/; Stand: 16.09.2014

40 Empfehlungen für die Diagnostik und Therapie des Endometriumkarzinoms. 2011. Online: www.ago-online.de; last access: 16.09.2014
41 Querleu D, Planchamp F, Narducci F et al.; Institut National du Cancer; Societe Francaise d'Oncologie Gynecologique. Clinical practice guidelines for the management of patients with endometrial cancer in France: recommendations of the Institut National du Cancer and the Société Française d’Oncologie Gynécologique. Int J Gynecol Cancer 2011; 21: 945-950

42 Laparoscopic hysterectomy (including laparoscopic total hysterectomy and laparoscopically assisted vaginal hysterectomy) for endometrial cancer. 2010. NICE interventional procedure guidance 356. Online: www.nice.org.uk/ipg356; last access: 16.09.2014

43 Solomayer E-F, Juhasz-Böss I, Becker S et al. Aktueller Stellenwert der Laparoskopie in der Therapie des frühen Endometriumkarzinoms. Geburtsh Frauenheilk 2008; 68: 1025-1027

44 Juhasz-Böss I, Runnebaum I. Stellenwert der Laparoskopie beim Endometriumkarzinom. Der Onkologe 2012; 10: 883-890

45 Tinelli R, Litta P, Meir Y et al. Advantages of laparoscopy versus laparotomy in extremely obese women (BMI > 35) with early-stage endometrial cancer: a multicenter study. Anticancer Res 2014; 34: 2497-2502

46 Gunderson CC, Java J, Moore KN et al. The impact of obesity on surgical staging, complications, and survival with uterine cancer: a Gynecologic Oncology Group LAP2 ancillary data study. Gynecol Oncol 2014; 133: 23-27

47 Altgassen C, Hertel H, Brandstädt A et al.; AGO Study Group. Multicente validation study of the sentinel lymph node concept in cervical cancer: AGO Study Group. J Clin Oncol 2008; 26: 2943-2951

48 Cibula D, Abu-Rustum NR, Dusek L et al. Bilateral ultrastaging of sentinel lymph node in cervical cancer: lowering the false-negative rate and improving the detection of micrometastasis. Gynecol Oncol 2012; 127: 462-466

49 Ansari M, Rad MA, Hassanzadeh $M$ et al. Sentinel node biopsy in endometrial cancer: systematic review and meta-analysis of the literature. Eur J Gynaecol Oncol 2013; 34: 387-401

$50 \mathrm{Kim}$ CH, Soslow RA, Park KJ et al. Pathologic ultrastaging improves micrometastasis detection in sentinel lymph nodes during endometrial cancer staging. Int J Gynecol Cancer 2013; 23: 964-970

51 Kang S, Yoo HJ, Hwang JH et al. Sentinel lymph node biopsy in endometrial cancer: meta-analysis of 26 studies. Gynecol Oncol 2011; 123: 522-527

52 Frumovitz M, Coleman RC, Soliman PT et al. A case for caution in the pursuit of the sentinel node in women with endometrial carcinoma. Gynecol Oncol 2014; 132: 275-279

$53 \mathrm{Abu}$-Rustum NR. Update on sentinel node mapping in uterine cancer: 10-year experience at Memorial Sloan-Kettering Cancer Center. J Obstet Gynaecol Res 2014; 40: 327-334

54 Brucker SY, Taran FA, Wallwiener D. Sentinel lymph node mapping in endometrial cancer: a concept ready for clinical routine? Arch Gynecol Obstet 2014; 290: 9-11

55 Juhasz-Böss I, Mallmann P, Möller CP et al. Use of laparoscopy in the treatment of endometrial and cervical cancer - results of a 2012 Germany-wide survey. Geburtsh Frauenheilk 2013; 73: 911-917

56 Neis KJ. Laparoskopische Operation von Ovarialtumoren, Leitlinien der Gynäkologie und Geburtshilfe Band 1. Berlin: Deutsche Gesellschaft für Gynäkologie und Geburtshilfe ev.; 2008

57 Leitlinienprogramm Onkologie (Deutsche Krebsgesellschaft, Deutsche Krebshilfe, AWMF). S3-Leitlinie Diagnostik, Therapie und Nachsorge maligner Ovarialtumoren, AWMF Registrierungsnummer: 032-035OL. Online: http://leitlinienprogramm-onkologie.de/Leitlinien.7.0.html; last access: 16.09 .2014

58 Reich H, McGlynn F, Wilkie W. Laparoscopic management of stage I ovarian cancer. A case report. J Reprod Med 1990; 35: 601-604; discussion 604-605

59 Querleu D, LeBlanc E. Laparoscopic infrarenal paraaortic lymph node dissection for restaging of carcinoma of the ovary or fallopian tube. Cancer 1994; 73: 1467-1471

60 Lawrie TA, Medeiros LR, Rosa DD et al. Laparoscopy versus laparotomy for FIGO stage I ovarian cancer. Cochrane Database Syst Rev 2013; 2: CD005344

61 Nezhat $F$, Lavie R, Lavie $O$. The role of minimally invasive surgery in ovarian cancer. Int J Gynecol Cancer 2013; 23: 782-783

62 Canis M, Wattiez A, Mage G et al. Laparoscopic management of adnexal masses. Baillieres Clin Obstet Gynaecol 1994; 8: 7

63 Canis M, Jardon K, Niro J et al. [Endoscopic management of gynecological malignancies: an update. 2007]. Bull Acad Natl Med 2007; 191: 1357-1365; discussion 1365-1366 
64 Brockbank EC, Harry V, Kolomainen D et al. Laparoscopic staging for apparent early stage ovarian or fallopian tube cancer. First case series from a UK cancer centre and systematic literature review. Eur J Surg Oncol 2013; 39: 912-917

65 Montanari G, Di Donato N, Del Forno S et al. Laparoscopic management of early stage ovarian cancer: is it feasible, safe, and adequate? A retrospective study. Eur J Gynaecol Oncol 2013; 34: 415-418

66 Park HJ, Kim DW, Yim GW et al. Staging laparoscopy for the management of early-stage ovarian cancer: a metaanalysis. Am J Obstet Gynecol 2013; 209: 58.e1-58.e8

67 Chi DS, Abu-Rustum NR, Sonoda Y et al. The safety and efficacy of laparoscopic surgical staging of apparent stage I ovarian and fallopian tube cancers. Am J Obstet Gynecol 2005; 192: 1614-1619

68 Lee M. Comparisons of surgical outcomes, complications, and costs between laparotomy and laparoscopy in early-stage ovarian cancer. Int J Gynecol Cancer 2011; 21: 251-256
69 Koo YJ, Kim JE, Kim YH et al. Comparison of laparoscopy and laparotomy for the management of early-stage ovarian cancer: surgical and oncological outcomes. J Gynecol Oncol 2014; 25: 111-117

70 Bogani G, Cromi A, Serati M et al. Laparoscopic and open abdominal staging for early-stage ovarian cancer: our experience, systematic review, and meta-analysis of comparative studies. Int J Gynecol Cancer 2014; 24: 1241-1249

71 Fagotti A, Vizzielli G, Fanfani F et al. Introduction of staging laparoscopy in the management of advanced epithelial ovarian, tubal and peritoneal cancer: impact on prognosis in a single institution experience. Gynecol Oncol 2013; 131: 341-346

72 Rutten MJ, Leeflang MM, Kenter GG et al. Laparoscopy for diagnosing resectability of disease in patients with advanced ovarian cancer. Cochrane Database Syst Rev 2014; 2: CD009786 